\title{
Creation of Neonatal Hemodynamics Research Center: building capacity for echocardiography-based science in neonatology
}

\author{
(c) The Author(s), under exclusive licence to the International Pediatric Research Foundation, Inc 2021
}

Pediatric Research (2022) 91:1306-1307; https://doi.org/10.1038/ s41390-021-01685-2

The Neonatal Hemodynamics Research Center (NHRC) was recently established to create a virtual and immersive learning environment by bringing together scientific thought leaders from the fields of neonatal hemodynamics and echocardiography. One of the challenges of the contemporary approach to cardiovascular care in the neonatal intensive care unit (NICU) is imprecision in the selection of cardiovascular therapeutics, which is often based on non-specific clinical symptoms and without scientific validation or evidence-based guidelines. This relates, at least in part, to a narrow mechanistic understanding of common neonatal cardiovascular problems, limited access to longitudinal echocardiography, and insufficient scientific knowledge as to the timing and indications for echocardiography in the NICU and its clinical applicability. The absence of scientific validation of measures of cardiovascular function in newborns and lack of standardized integration of echocardiography techniques in research design further hinders diagnostic precision and optimization of therapeutic interventions. In addition, variance in disease characterization has led to medical uncertainty in the approach to common neonatal problems and on occasion therapeutic nihilism. ${ }^{1,2}$ Optimal use of functional echocardiography, when coupled with training in neonatal cardiovascular physiology, may enable better appraisal of ambient physiology, provide enhanced mechanistic insights and phenotypic characterization, and facilitate the choice of disease/physiology-specific pharmacological interventions. ${ }^{3}$ Given these considerations, the past two decades have witnessed substantial growth in the field of neonatal hemodynamics with the emergence of a number of scientific thought leaders, the establishment of clinical and academic neonatal functional echocardiography and hemodynamic programs globally, and the development of partnerships with pediatric cardiologists. The publication of guidelines for the use of targeted neonatal echocardiography and neonatologist performed echocardiography, as a constructive collaboration between neonatology and pediatric cardiology leaders, was a foundational step in the field. ${ }^{4}$

Translation of hemodynamic research to the bedside, however, is challenging for several reasons. First, imaging techniques and novel methods require validation and reliability testing in both preterm and term infants. Second, robust normative reference datasets are needed to understand deviations from normal health. Third, enhanced mechanistic insights are needed into common neonatal problems such as patent ductus arteriosus, pulmonary hypertension, and shock to determine population of interest and characterize the effects of therapeutic intervention. Changing the paradigm in neonatal hemodynamic care requires generation of disease-specific scientific insights and evidence of treatment effects in studies that are appropriately designed, powered, and targeted to the population of interest. These challenges are further compounded by the variance in fundamental cardiovascular physiology knowledge by providers, the limited and variable access to expert training in neonatal cardiovascular physiology, and the paucity of interactive hemodynamic educational forums. ${ }^{5}$ Therefore, in 2019 an independent virtual collaborative international platform, the NHRC [www.neonatalhe modynamics.com], was founded with the intention to foster collaboration and networking between hemodynamic researchers from different centers, not limited by the geo-political boundaries. The long-term vision of the NHRC is to address the gaps in the care of newborns with acute and chronic hemodynamic complications and the need for high-quality evidence and education for neonatal clinicians and trainees. Its mission is to bring together the major academic centers in the field of neonatal hemodynamics under one collaborative umbrella and facilitate high-quality educational, research, and quality improvement work focused on improving the hemodynamic care provided to neonates in intensive care units across the globe. After 3 years of sustained efforts, the NHRC has reached the milestone of including the majority of tertiary centers across North America and Europe with an active clinical and/or research neonatal hemodynamic program, 37 centers and $\sim 70$ faculty members with relevant expertise, and is kick-starting its global educational academic activities (Fig. 1).

Several additional factors motivated the creation and current structure of the NHRC. First, a peer-review gap was perceived in the provision of advice on hemodynamics research study design and investigator-initiated hemodynamics grant proposals. Many early career hemodynamics researchers appeared to be working independently within their center and had limited access to scientific mentorship; often, their first encounter with formative scientific critique was at the peer review stage of the article submission process. Through receipt of formative guidance early in the development stage of study design and the inclusion of a suitable testable hypothesis and related methodology, the quality of hemodynamics studies being conducted may be enhanced and lead to an improved and reliable understanding of neonatal cardiovascular health and disease. Second, limitations were perceived in the educational curriculums across regions. At many sites trainees are exposure to a single teacher and/or have variable access to less common disease states, particularly in low-volume centers. Through the development of an online common education curriculum, delivered by a diverse group of world-renowned neonatal hemodynamics and pediatric cardiology faculty, hemodynamic trainees across regions will gain access to a comprehensive and standardized education. Specific methods will include interactive case-based physiology reviews, a hemodynamics journal club, and interactive lectures, all of which will be delivered virtually to ensure broad dissemination of new knowledge and scientific updates and align with the unique needs of learners in the year 2021. The virtual multimodal format will also enable increased proximity between learners and current hemodynamic scientific thought leaders, providing grounds for new collaborations and mentor-mentee relationships. Above all, the NHRC seeks to deeply engage with its stakeholders, the frontline neonatal clinicians, neonatal trainees, and patient advocacy groups, by hosting diverse systematic educational activities on its platform, providing one-stop access to hemodynamic fellowship and other learning 


\begin{tabular}{|c|c|c|c|}
\hline \multicolumn{2}{|c|}{ NEONATAL HEMODYNAMICS RESEARCH CENTEF } & & $\begin{array}{l}\text { NEONATAL } \\
\text { HEMODYNAMICS }\end{array}$ \\
\hline \multicolumn{2}{|c|}{$\begin{array}{l}\text { Opportunities for NHRC members } \\
\text { - Access to an international platform to showcase } \\
\text { regional programs' focus and achievements } \\
\text { Regular opportunities to present academic work to } \\
\text { multidisciplinary audiences } \\
\text { - Regular opportunities to engage in educational and } \\
\text { academic committees striving to advance the field } \\
\text { - Access to formal guidance and feedback on planned } \\
\text { research and grant proposals and broad } \\
\text { administrative guidance for the development of new } \\
\text { clinical and academic programs } \\
\text { Opportunities to develop, lead, and/or collaborate in } \\
\text { multi-site research projects }\end{array}$} & \multicolumn{2}{|c|}{$\begin{array}{l}\text { Opportunities for NHRC site users } \\
\text { - Access to a robust educational curriculum taught by } \\
\text { international experts for trainees and clinicians } \\
\text { interested in neonatal cardiovascular medicine and } \\
\text { echocardiography } \\
\text { - Access to a schedule of related hemodynamic } \\
\text { events (virtual and in person) } \\
\text { - One-stop access to global fellowship opportunities } \\
\text { - Access to a directory of site-specific and NHRC } \\
\text { consensus clinical practice guidelines } \\
\text { Insight into hemodynamic research undertaken at } \\
\text { NHRC sites \& cross-regional collaborations }\end{array}$} \\
\hline EDUCA & \multicolumn{2}{|c|}{ RESEARCH } & QUALITY IMPROVEMENT \\
\hline $\begin{array}{l}\text { Support trainees and clinicians with a } \\
\text { comprehensive educational curriculum: } \\
\text { I. Core TnECHO/NPE curriculum } \\
\text { II. Global education rounds } \\
\text { III. Hemodynamic cases \& journal club }\end{array}$ & $\begin{array}{l}\text { Raise the quality } \\
\text { hemodynamic re } \\
\text { cross-regional co } \\
\text { providing access } \\
\text { mentorship acros } \\
\text { boundaries }\end{array}$ & $\begin{array}{l}\text { neonatal } \\
\text { arch by leveraging } \\
\text { borations and } \\
\text { systematic } \\
\text { geographical }\end{array}$ & $\begin{array}{l}\text { Achieve academic oversight in the } \\
\text { field by commissioning development } \\
\text { of evidence-based clinical guidelines } \\
\text { and consensus-based practice } \\
\text { statements }\end{array}$ \\
\hline
\end{tabular}

Fig. 1 The pillars of the Neonatal Hemodynamics Research Centre's long-term vision. The three pillars of the Neonatal Hemodynamics Research Center (NHRC)'s long-term vision: the delivery of a robust education curriculum for trainees and clinicians, the fostering of high quality collaborative research, and the generation of state-of-the-art evidence-based practice guidelines and consensus-based position statements directed toward improving neonatal hemodynamics care.

opportunities, developing and publishing evidence-based guidelines and consensus practice statements, and providing career, administrative, and research mentorship to its members. The virtual platform showcases the academic and clinical activities of its member sites to enable broader dissemination of echocardiography-related research and access to site-specific clinical guidelines. Through the creation of specific research, education, and clinical guideline working groups, all members will have an opportunity to participate in and learn from NHRC activities, have the opportunity to make a meaningful contribution to development of the field, increase their networking and collaborative potential, and explore leadership opportunities.

In summary, the creation of the NHRC's virtual academic interface minimizes boundaries between learners and thought leaders in the field of neonatal hemodynamics. In addition, the extension of the global education and scientific scope will enhance the quality of scientific work by maximizing diversity and inclusiveness. These benefits will enable the creation of a strong academic foundation for the field of neonatal hemodynamics by leveraging cross-regional collaborations and facilitating the development of large international datasets and clinical trials, all the while fostering the next generation of academic leaders.

Laura Thomas ${ }^{1,2,3}$, Patrick J. McNamara ${ }^{4,5,6}$ and Amish Jain ${ }^{1,2,7,8}$ 圠

${ }^{1}$ Department of Paediatrics, Mount Sinai Hospital, Toronto, ON,

Canada. ${ }^{2}$ Lunenfeld-Tanenbaum Research Institute, Mount Sinai

Hospital, Toronto, ON, Canada. ${ }^{3}$ Department of Newborn and

Developmental Paediatrics, Sunnybrook Health Sciences Center,

Toronto, ON, Canada. ${ }^{4}$ Department of Pediatrics, Stead Family

Children's Hospital, lowa City, IA, USA. ${ }^{5}$ Department of Pediatrics,

University of lowa, lowa City, IA, USA. ${ }^{6}$ Department of Internal

Medicine, University of lowa, lowa City, IA, USA. ${ }^{7}$ Department of Paediatrics, University of Toronto, Toronto, ON, Canada.

${ }^{8}$ Department of Physiology, University of Toronto, Toronto, ON, Canada. ${ }^{凶}$ email: amish.jain@sinaihealth.ca

\section{REFERENCES}

1. Benitz, W. E. Hey, Doctor, leave the PDA alone. Pediatrics 140, e20170566 (2017).

2. Barrington, K., El-Khuffash, A. \& Dempsey, E. Intervention and outcome for neonatal hypotension. Clin. Perinatol. 47, 563-574 (2020).

3. El-Khuffash, A., Herbozo, C., Jain, A., Lapointe, A. \& McNamara, P. J. Targeted neonatal echocardiography ( $\mathrm{TnECHO}$ ) service in a Canadian neonatal intensive care unit: a 4-year experience. J. Perinatol. 33, 687-690 (2013).
4. Mertens, L. et al. Targeted neonatal echocardiography in the neonatal intensive care unit: practice guidelines and recommendations for training. Writing Group of the American Society of Echocardiography (ASE) in collaboration with the European Association of Echocardiography (EAE) and the Association for European Pediatric Cardiologists (AEPC). J. Am. Soc. Echocardiogr. 24, 1057-1078 (2011).

5. Finan, E., Sehgal, A., Khuffash, A. E. \& McNamara, P. J. Targeted neonatal echocardiography services: need for standardized training and quality assurance. $J$. Ultrasound Med. 33, 1833-1841 (2014).

\section{ACKNOWLEDGEMENTS}

We would like to acknowledge all of the members that have come together to form the Neonatal Hemodynamic Research Center (NHRC). A complete faculty and trainee list can be found at https://neonatalhemodynamics.com.

\section{AUTHOR CONTRIBUTIONS}

Each author has met the Pediatric Research authorship requirements listed below. All authors completed the following: substantial contributions to conception and design, acquisition of data, or analysis and interpretation of data; drafting the article or revising it critically for important intellectual content; and final approval of the version to be published.

\section{FUNDING}

The Neonatal Hemodynamics Research Center website redevelopment was supported through an unrestricted educational grant from Medical Informatics and Intel.

\section{ETHICS APPROVAL AND CONSENT TO PARTICIPATE}

No patient consent was obtained for this work.

\section{COMPETING INTERESTS}

The authors declare no competing interests.

\section{ADDITIONAL INFORMATION}

Correspondence and requests for materials should be addressed to A.J.

Reprints and permission information is available at http://www.nature.com/ reprints

Publisher's note Springer Nature remains neutral with regard to jurisdictional claims in published maps and institutional affiliations. 